\title{
The national lung health framework: an opportunity for gender analysis
}

\author{
N Hemsing, MA (1); L Greaves, PhD (2)
}

\begin{abstract}
Smoking related respiratory diseases in Canada represent a huge social and economic burden for both women and men. This article addresses the potential impact of the National Lung Health Framework for reducing disparities between women and men in respiratory health and between sub-populations of women and men. A preliminary analysis of the existing framework documents indicates that sex and gender factors, differences and influences have not yet been clearly or sufficiently identified. Yet, there are sex and gender issues related to tobacco prevention and cessation, lung health and lung disease. In particular, we consider the specific respiratory health needs and experiences of women to demonstrate the need for sex and gender-based analysis within the framework. For example, while there is inconsistent evidence regarding quit rates, women and men have different cessation patterns and reasons for smoking. Although creating a Canada-specific approach to lung health is an important initiative, the sex and gender issues associated with respiratory disease and health need to be explicitly addressed in the planning and development stages of the framework in order to have a beneficial and lasting impact on both women and men.
\end{abstract}

Key words: smoking, respiratory diseases, National Lung Health Framework, NLHF, chronic obstructive pulmonary disease, COPD, sex, gender, women

\section{Introduction}

Respiratory diseases in Canada represent a huge social and economic burden. Lung cancer, chronic obstructive pulmonary disease (COPD) and pneumonia, the three leading respiratory causes of death in Canada, were responsible for $15.6 \%$ of deaths in men and $13.5 \%$ of deaths in women in $2004 .^{1}$ The current planning and development of a National Lung Health Framework (NLHF) is an integral step to improving the respiratory health of Canadians. This framework emerged in March 2006 from a workshop entitled "Breathing Matters," which united stakeholders in the mandate to develop a national action plan to improve respiratory health in Canada. Under the auspices of the Canadian Lung Association, the process is being led by an interim steering committee that has coordinated subsequent workshops to guide the framework-development process. ${ }^{2}$ Released in August 2008, the NLHF document will be used to form an action plan and guide decision makers and stakeholders in strategic planning. $^{3}$
The creation of a comprehensive framework has the potential to improve the respiratory health of Canadian women and men from prevention to diagnosis, management and treatment. The framework also seeks to address some of the health challenges facing diverse sub-populations of Canadians. For example, the documents produced during the framework development process specify the need to "[address] the needs of vulnerable populations," and consistently identify First Nations persons, youth and immigrants as important sub-populations for respiratory health initiatives. ${ }^{4}$ The four key strategies in the framework document, ${ }^{i}$ which deal with everything from health promotion and disease detection to policy and research, indicate that actions must aim to not only improve overall health, but also the disparities between Aboriginal and non-Aboriginal populations. ${ }^{3}$ The steering committee has identified many research-and practice-based issues, such as the importance of examining relationships between respiratory health, vulnerable populations and environmental factors, and the need to improve provider-patient support and increase the use of spirometry as a diagnostic tool. ${ }^{3,4}$

Developing a national framework is a significant challenge, given the wide range of acute and chronic respiratory conditions affecting Canadians. These include diseases as varied as asthma, tuberculosis, sleep apnea, pneumonia, influenza, COPD and lung cancer, each of which have

i (1) health promotion, awareness and disease prevention; 2) disease detection and management; 3) policy, partnerships and community/ systems support; 4) research, surveillance and knowledge translation

Author References

1 British Columbia Centre of Excellence for Women's Health

2 British Columbia Centre of Excellence for Women's Health

Correspondence: Natalie Hemsing, E311-4500 Oak Street, P.O. Box 48, Vancouver, BC V6H 3N1, Tel.: 604-875-2424 ext. 3793, Fax: 604-875-3716, Email: nhemsing@cw.bc.ca 
unique causal, diagnostic, management and treatment issues. Furthermore, these four issues vary between women and men, and among sub-populations of women and men. Hence, the sex and gender issues associated with respiratory disease and health need to be explicitly addressed in the framework in order to have a beneficial and equitable impact for both women and men. However, a preliminary analysis of the existing framework documents ${ }^{2-5}$ indicates that sex and gender factors, and diversity related differences and influences have not been sufficiently identified, and that sex and gender analysis is not identified as a key analytical tool for strategic planning. In response to this lack, this article examines some of the respiratory health needs of women to highlight how these omissions within the current framework may fail to capture sex- and gender-based differences between women and men.

\section{Why integrate a sex and gender lens?}

If significant improvements in lung health are to be made, sex and gender analysis must be an integral part of planning and program initiatives. Sex- and gender-based analysis (SGBA) is a tool that promotes consideration of a range of issues related to both the research process and the application of knowledge in program or policy development activities such as the NLHF. An SGBA is recommended by Health Canada's Women's Health Strategy, ${ }^{6}$ and is also integrated into the work of the World Health Organization (WHO). ${ }^{7}$ Using such an approach helps to improve our understanding of how the influences of sex (i.e. biological) and gender (i.e. social and cultural aspects) determine health and disease. The effectiveness of how we design and implement sex- and gendersensitive policies and programs is partially determined by such analyses. ${ }^{8}$ Utilizing SGBA would allow the national strategy to address the unequal distribution of disease among women and men and among subpopulations of women and men, including Aboriginal groups and those with low incomes.
The reviewed documents underpinning the $\mathrm{NLHF}^{2,4,5}$ fail to clearly or consistently articulate a sex- or gender-based approach; nor do they indicate whether sex or gender has informed the development or implementation processes. Occasionally, the differences between women's and men's respiratory health needs and issues are discussed. Importantly, the increasing smoking rates in women are identified as a timely issue, ${ }^{3,5}$ as is the growing prevalence among women of COPD and lung cancer, in part due to the relative lag in women's smoking compared to men. ${ }^{3}$ In addition, pregnant women are cited as an important population when creating cessation programs. ${ }^{5}$ Yet the mention of women in the NLHF documents is additive and sporadic in comparison to other populations such as youth, First Nations people and immigrants, ${ }^{3,4}$ and the need to examine the specific health needs of women and men and sub-populations of women and men is not consistently identified. Overlooked in the NHLF is the fact that all populations are gendered, and their health concerns need to be addressed accordingly.

\section{Sex and gender influences on lung health}

Numerous sex- and gender-based influences and factors must be considered to develop a framework that addresses respiratory health needs. To illustrate this point, we consider some of these needs, focussing on the context of women's respiratory disease prevention, diagnosis and treatment issues. For example, many respiratory diseases affect women and men disproportionately. Women have higher rates of asthma, COPD is increasingly becoming a woman's disease, and mortality rates for lung cancer have been increasing among women in Canada since 1987, yet decreasing among men. ${ }^{1}$ There are also more lung cancers among women who have never smoked, compared to men who have never smoked..$^{9,10}$ Furthermore, certain subpopulations of girls and women, including low socio-economic groups and non-white minorities, have disproportionately higher rates of respiratory disease. Non-white and low-income women tend to have less access to health care resources and suffer more often from disease and disabilities. ${ }^{11,12}$
Tobacco use is a key factor in the development of respiratory disease. Gendered patterns of smoking and exposure to smoke, and biological, hormonal and genetic factors overlap and influence women's susceptibility to respiratory diseases. ${ }^{13}$ Estrogen may influence the metabolism of cigarette smoke, resulting in increased damaging effects. ${ }^{10,12,14-16}$ Evidence shows that women who smoke less than men show similar levels of impaired lung function, and smoking decreases women's lung function more than men's. ${ }^{12,17,18}$ Meanwhile, tobacco marketing has been gendered, effectively and increasingly targeting women, portraying smoking as glamorous and as a method to stay thin. ${ }^{19,20}$ The industry has also developed genderspecific tobacco products. Many women have been marketed "light" cigarettes with higher yields of N-nitrosamines, which may be partially responsible for the increased lung cancer rates in women. ${ }^{12}$ Second hand smoke also impacts women differently than men, given the lag in overall smoking trends between men and women is resulting in more non-smoking women living with men who smoke. ${ }^{19,21}$

There are also sex and gender issues associated with diagnosis. Women and men report different symptoms and women develop COPD at a younger age. ${ }^{12}$ Women are also less likely to report sputum production than men, due to gendered norms and ideals. ${ }^{22}$ In addition, women are often under-diagnosed or misdiagnosed for certain diseases, due to these differences in presentation as well as gender bias in the health system. For example, women with COPD are more often diagnosed with asthma than men. ${ }^{13,23}$ Moreover, even when women and men present the same symptoms, providers may not interpret symptoms in the same way. ${ }^{24}$

In general, compared to men, women with respiratory diseases tend to report more hospitalizations, more limitations in activity and higher rates of anxiety and depression associated with respiratory diseases. ${ }^{1,23,25-29}$ Changes in physical appearance associated with COPD and lung cancer may be especially troubling for women, who are encouraged to meet gendered social standards of beauty. ${ }^{28}$ Finally, pulmonary 
rehabilitation has been shown to be more effective for men over time. ${ }^{22}$ All of these factors shape women's and men's lung health from prevention to treatment and need to be addressed and included within the planning stages to produce a framework that will significantly improve women's and men's respiratory health.

\section{Conclusion}

The NLHF can significantly improve the dissemination and uptake of knowledge related to respiratory health by drawing links between sex- and gender-specific research in both tobacco use and exposure, as well as respiratory health and disease. There is a clear need for the integration of spheres of knowledge on tobacco, gender, and respiratory disease. ${ }^{12}$ The highest rates of mortality are associated with diseases that are primarily associated with smoking or smoke exposure, such as COPD and lung cancer. There is inconsistent evidence regarding gender differences in cessation. ${ }^{\text {ii }}$ Regardless, women and men do smoke for different reasons and have different cessation patterns. ${ }^{20}$ One potential strategy for addressing some of these issues is the formation of a NLHF working group on sex, gender and diversity issues, which could include researchers and decision makers in lung health, women's health, men's health and tobacco use and prevention. Connections must be strengthened between research, programs and policy so that emerging sex- and gender-specific findings are effectively translated to health care settings and decision makers. ${ }^{40}$ By addressing these and other sex- and gender-related factors, the NLHF could lead the way in effectively responding to all "vulnerable" groups.

The identification of sex- and genderbased analysis as a key analytic tool would encourage researchers, decision makers and other stakeholders to account for these differences. In sum, there are different reasons why women smoke, as well as varying experiences of care and treatment for respiratory disease, both compared to men and among sub-populations of women. We have discussed some of the unique respiratory health concerns of women in particular to make a case for a more detailed, consistent and mainstreamed need for a sex and gender lens to guide the NLHF and action plan. The full and comprehensive implementation of a sex and gender analysis would also necessitate an exploration of the unique respiratory health needs of men, and contribute to a systematic assessment of gendered responses aimed at men. The NLHF can seek to improve the respiratory health of all groups, through the creation of initiatives to support and encourage further sex and gender-based research and interventions. Although very little research has examined specific respiratory health issues for subpopulations, such as people on low incomes or of particular ethnic groups, the NLHF can address and respond to these issues by utilizing an SGBA to encourage thought on women in Canada and steer Canada toward future sex-, gender- and diversitybased research, programming, policy and analysis.

\section{Acknowledgements}

This commentary is based on an evidence review on women's respiratory health, prepared for and funded by the Provincial Health Services Authority (PHSA) Population and Public Health Program. The activities of the British Columbia Centre of Excellence for Women's Health are made possible through a financial contribution from Health Canada. However, the views expressed are those of the authors and not necessarily those of PHSA or Health Canada.

\section{References}

1. Public Health Agency of Canada. Life and breath: respiratory disease in Canada. Ottawa: Public Health Agency of Canada; 2007.

2. Canadian Lung Association. Leading. Acting. Together. Building Canada's first national lung health action plan: report from the all-stakeholder workshop on lung health. Paper presented at: All-stakeholder workshop on lung health. 2007 April 26-27; Ottawa, Canada.

3. Canadian Lung Association. National lung health framework. Ottawa: Canadian Lung Association; 2008.

4. Canadian Lung Association. Respiratory health in Canada asset map: preliminary report. Ottawa: Canadian Lung Association; 2007.

5. de Lusignan $\mathrm{S}$, Chan $\mathrm{T}$, Cohen $\mathrm{A}$, Thana L, Hague N, van Vlymen J. Health education and prevention for people with severe mental illness: a cross-sectional study of general practice computer records. Primary care mental health. 2005;3(3):221-33.

6. Health Canada. Women's health strategy. Ottawa: Health Canada; 1999.

7. World Health Organization. The WHO gender mainstreaming strategy. Geneva: WHO. Retrieved August 18, 2008 from: http://www.who.int/gender/ mainstreaming/strategy/en/index.html.

8. Health Canada. Exploring concepts of gender and health. Ottawa: Health Canada; 2003.

9. Patel JD, Bach PB, Kris MG. Lung cancer in US women: a contemporary epidemic. JAMA. 2004;291:1763-768.

10. Tang DL, Rundle A, Warburton D, et al. Associations between both genetic and environmental biomarkers and lung cancer:

ii Although evidence from CTUMS (2006) shows that in Canada, women (60.1\%) have slightly higher quit rates than men (57.9\%), studies examining gender differences in quit rates often reveal that women have lower quit rates, more difficulty quitting smoking and greater relapse rates than men. ${ }^{30.36}$ Yet, other evidence suggests that gender differences are minimal or non-existent, ${ }^{37,38}$ or that it is, in fact, men who have lower quit rates and greater difficulty quitting smoking. ${ }^{39}$ 
evidence of a greater risk of lung cancer in women smokers. Carcinogenesis. 1998;19: 1949-953.

11. Steele CB, Richmond-Reese V, Lomax S. Racial and ethnic disparities in HIV/AIDS, sexually transmitted diseases, and tuberculosis among women. J Womens Health. 2006;15(2):116-22.

12. Greaves LJ, Richardson LA. Tobacco use, women, gender, and chronic obstructive pulmonary disease: are the connections being adequately made? Proc Am Thorac Soc. $2007 ;$ 4:675-79.

13. Caracta C. Gender differences in pulmonary disease. Mt Sinai J Med. 2003; 70(4):215-24.

14. Zang EA, Wynder EL. Differences in lung cancer risk between men and women: examination of the evidence. J Natl Cancer Inst. 1996;88(3/4):183-92.

15. Ben-Zaken Cohen S, Pare PD, Man SFP, Sin DD. The growing burden of chronic obstructive pulmonary disease and lung cancer in women: examining sex differences in cigarette smoke metabolism. Am J Respir Crit Care Med. 2007;176:113-20.

16. Sin DD, Cohen SB-Z, Day A, Coxson H, Pare PD. Understanding the biological differences in susceptibility to chronic obstructive pulmonary disease between men and women. Proc Am Thorac Soc. 2007;4:671-74.

17. Prescott E, Bjerg AM, Andersen PK, Lange P, Vestbo J. Gender difference in smoking effects on lung function and risk of hospitalization for COPD: results from a Danish longitudinal population study. Eur Respir J. 1997;10:822-27.

18. Canadian Lung Association. Women and COPD: a national report. Ottawa: Canadian Lung Association; 2006.

19. Ernster V, Kaufman N, Nichter M, Samet J, Yoon SY. Women and tobacco: moving from policy to action. Bull World Health Organ. 2000;78(7):891-901.
20. Sarna L, Aguinaga Bialous S. Why tobacco is a women's health issue. Nurs Clin North Am. 2004;39(1):165-80.

21. Siegfried JM. Women and lung cancer: does oestrogen play a role? Lancet Oncol. 2001;2(8):506-513.

22. Camp PG, Goring SM. Gender and the diagnosis, management, and surveillance of chronic obstructive pulmonary disease. Proc Am Thorac Soc. 2007;4:686-91.

23. French CT, Fletcher KE, Irwin RS. Gender differences in health-related quality of life in patients complaining of chronic cough. Chest. 2004;125:482-88.

24. Chapman KR, Tashkin DP, Pye DJ. Gender bias in the diagnosis of COPD. Chest. 2001; 119:1691-695.

25. Sinclair A, Tolsma D. Gender differences in asthma experience and disease care in a managed care organization. J Asthma. 2006;40(8):945-53.

26. Belloch A, Perpiñá M, Martínez-Moragón E, de Diego A, Martínez-Francés M. Gender differences in health-related quality of life among patients with asthma. J Asthma. 2003;40(8):945-53.

27. Woods S, Sorscher J, King J, Hasselfeld K. Young adults admitted for asthma: does gender influence outcomes? J Womens Health. 2003;12(5):481-85.

28. Johnson JL, Campbell AC, Bowers M, Nichol A-M. Understanding the social consequences of chronic obstructive pulmonary disease: the effects of stigma and gender. Proc Am Thorac Soc. 2007;4:680-82.

29. Sarna L, Brown JK, Cooley ME, et al. Quality of life and meaning of illness of women with lung cancer. Oncol Nurs Forum. 2005;32(1):E9-19.

30. Scharf DS. Are there gender differences in smoking cessation, with and without bupropion? Pooled- and meta-analyses of clinical trials of Bupropion SR. Addiction. 2004; 99:1462-469.
31. Bohadana A, Nilsson F, Rasmussen T, Martinet Y. Gender differences in quit rates following smoking cessation with combination nicotine therapy: influence of baseline smoking behavior. Nicotine Tob Res. 2003;5(1):111-16

32. Bjornson W, Rand C, Connett JE, et al. Gender differences in smoking cessation after 3 years in the lung health study. Am J Public Health. 1995; 85:223-30.

33. Westmaas JL, Langsam K. Unaided smoking cessation and predictors of failure to quit in a community sample: effects of gender. Addict Behav. 2005;30(7):1405-424.

34. Ward KD, Klesges RC, Zbikowski SM, Bliss RE, Garvey AJ. Gender differences in the outcome of an unaided smoking cessation attempt. Addict Behav. 1997; 22(4):521-33.

35. Wetter D, Kenford S, Smith S, Fiore M, Jorenby D, Baker T. Gender differences in smoking cessation. J Consult Clin Psychol. 1999;67(4):555-62.

36. Osler M, Prescott E, Godtfredsen N, Hein H, Schnohr P. Gender and determinants of smoking cessation: a longitudinal study. Prev Med. 2000;29(1):57-62.

37. Killen J, Fortmann S, Varady A, Kraemer H. Do men outperform women in smoking cessation trials? Maybe, but not by much. Exp Clin Psychopharmacol. 2002;10(3): 295-301.

38. Etter J-F, Prokhorov A, Perneger TV Gender differences in the psychological determinants of cigarette smoking. Addiction. 2002;97(6):733-43.

39. Walsh PM, Carrillo P, Flores G, Masuet C, Morchon S, Ramon JM. Effects of partner smoking status and gender on long term abstinence rates of patients receiving smoking cessation treatment. Addict Behav. 2007;32(1):128-36

40. Pederson AP, Hoyak KAK, Mills S, Camp PG Reflecting the changing face of chronic obstructive pulmonary disease: sex and gender in public education materials on COPD. Proc Am Thorac Soc. 2007; 4:683-85. 